\title{
Modelling pesticide transport with a three-site sorption sub-model: a field test
}

\section{J. J. T. I. Boesten}

Institute for Pesticide Research, P.O. Box 650, NL 6700 AR Wageningen, Netherlands

Received 27 April 1987; accepted 12 June 1987

Key words: modelling, pesticide sorption, pesticide transport

\begin{abstract}
Field measurements of the behaviour of the nematicide ethoprophos in the winter half-year were used to test a previously developed transport model in three soil types. In the model, the liquid phase is assumed to be homogeneous. The sorption sites are divided in three classes: sorption at class-1 sites is continuously in equilibrium with the liquid phase, whereas sorption equilibration at class- 2 and class- 3 sites takes place at time scales of days and months, respectively. The model explained the field-measured transport of ethoprophos satisfactorily. The effect of ignoring the long-term sorption equilibration process (i.e. sorption at class- 3 sites) on calculated concentration profiles was much smaller than that found in a study reported in the literature for the herbicide cyanazine in a loamy sand soil. It was shown that this difference in effect was related to a difference in the transformation rate coefficient.
\end{abstract}

\section{Introduction}

Transport of pesticides in soil is an important process, both from an agricultural point of view (efficacy against pests) and from an environmental point of view (e.g. leaching to groundwater). Previous results (Boesten, 1986) showed that a longterm sorption process (at a time scale of months) had a large influence on transport of pesticides as calculated with a mathematical model: ignoring the long-term process resulted in large discrepancies between calculated and measured concentration profiles in field experiments in spring and summer, whereas incorporating the process resulted in a good correspondence.

It is to be expected that a long-term sorption process is a general phenomenon for pesticide/soil systems. Back in 1972, in a review, Hamaker \& Thompson concluded that there was experimental evidence for a long-term sorption process. Recently, McCall \& Agin (1985) showed that sorption of the herbicide picloram in a range of soil types was much higher after $300 \mathrm{~d}$ of incubation than expected from short-term 
experiments.

Reports of field tests of transport models in which long-term sorption equilibration is considered, are very scarce. Smelt et al. (1981) carried out leaching experiments in the field with soil columns in winter for the nematicide ethoprophos. In these experiments they considered three soil types (from Wierum, Middenmeer and Rolde). Using data from this study, Leistra \& Smelt (1981) tested a transport model in which sorption equilibrium was assumed and in which long-term sorption was ignored, and found small but systematic discrepancies between calculated and measured transport. This paper describes how the data of Smelt et al. (1981) were used to further test the model developed recently (Boesten, 1986).

\section{The mathematical model}

Flow of water in soil was simulated with a revised version of the model developed by van Keulen (1975); see Boesten \& Stroosnijder (1986) for details.

In my model for pesticide transport, the liquid phase is assumed to be homogeneous. Three classes of sorption site (classes 1,2 and 3) are considered in the model. At equilibrium, sorption follows a Freundlich isotherm for each class. Sorption at class- 1 sites is assumed to be continuously at equilibrium, whereas sorption at class -2 and class- 3 sites is calculated from sorption rate equations:

$$
\begin{aligned}
& X_{1}=K_{1} c^{1 / n} \\
& \frac{\partial X_{2}}{\partial t}=k_{2}\left(K_{2} c^{1 / n}-X_{2}\right) \\
& \frac{\partial X_{3}}{\partial t}=k_{3}\left(K_{3} c^{1 / n}-X_{3}\right)
\end{aligned}
$$

in which $X_{1}, X_{2}$ and $X_{3}$ are contents sorbed $\left(\mathrm{kg} \mathrm{kg}^{-1}\right)$ at class-1, class-2 and class-3 sites, $t$ is time (d), $c$ is mass concentration in the liquid phase $\left(\mathrm{kg} \mathrm{m}^{-3}\right), K_{1}, K_{2}$ and $K_{3}$ are Freundlich coefficients $\left(\mathrm{m}^{3 / n} \mathrm{~kg}^{-1 / n}\right)$ for class- 1 , class- 2 and class- 3 sites, $1 / n$ is the Freundlich exponent, and $k_{2}$ and $k_{3}$ are desorption rate constants $\left(\mathrm{d}^{-1}\right)$ for class2 and class- 3 sites. The mass concentration in the soil system, $c^{*}\left(\mathrm{~kg} \mathrm{~m}^{-3}\right)$, is described by

$$
c^{*}=\theta c+\varrho\left(X_{1}+X_{2}+X_{3}\right)
$$

in which $\theta$ is volume fraction of water $\left(\mathrm{m}^{3} \mathrm{~m}^{-3}\right)$ and $\varrho$ is volumic mass of dry soil $(\mathrm{kg}$ $\left.\mathrm{m}^{-3}\right)$.

The mass flux of substance, $j\left(\mathrm{~kg} \mathrm{~m}^{-2} \mathrm{~d}^{-1}\right)$, is described by (see e.g. Bolt, 1982):

$$
j=J^{\mathrm{v}} c-\left(D_{\mathrm{dis}}+D_{\mathrm{dif}}\right) \partial c / \partial z
$$

in which $J^{v}$ is the volume flux of water $\left(\mathrm{m} \mathrm{d}^{-1}\right), D_{\mathrm{dis}}$ is the dispersion coefficient $\left(\mathrm{m}^{2}\right.$ 
$\left.\mathrm{d}^{-1}\right), D_{\text {dif }}$ is the diffusion coefficient $\left(\mathrm{m}^{2} \mathrm{~d}^{-1}\right)$ and $z$ is depth in soil (m). The dispersion coefficient is calculated using $D_{\text {dis }}=\left|J^{v}\right| L_{\text {dis }}$ in which $L_{\text {dis }}$ is the dispersion length (m). The coefficient for diffusion is calculated using $D_{\mathrm{dif}}=\lambda \theta D_{0}$ in which $\lambda$ is the tortuosity factor (1) and $D_{0}$ is the coefficient for diffusion of the pesticide in water $\left(\mathrm{m}^{2} \mathrm{~d}^{-1}\right)$.

The transformation of pesticide in the soil system is described by a first-order rate equation:

$$
R=k_{\mathrm{t}}^{*} c^{*}
$$

in which $R$ is the volumic mass rate of transformation $\left(\mathrm{kg} \mathrm{m}^{-3} \mathrm{~d}^{-1}\right)$ and in which $k_{\mathrm{t}}^{*}$ is the transformation rate coefficient $\left(\mathrm{d}^{-1}\right)$.

The mass conservation equation for the soil system is given by

$$
\frac{\partial c^{*}}{\partial t}=-\frac{\partial j}{\partial z}-R
$$

\section{Procedures}

\section{Field experiments}

Soil columns were sampled in the field in October 1978 at three sites in the Netherlands - near Wierum, Middenmeer, and Rolde (textural class of the three soils: silt loam, sandy loam and humous loamy sand, respectively). The length of the tubes in which the soil columns were collected was between 40 and $80 \mathrm{~cm}$ and the inner diameter was between 8 and $12 \mathrm{~cm}$. The tubes with the soil columns were dug into the soil beside the weather station Sinderhoeve near Renkum. At the end of October 1978 ethoprophos was mixed with the top $9 \mathrm{~cm}$ of the soil columns. The dose of ethoprophos was $4 \mathrm{mmol} / \mathrm{m}^{2}$ (i.e. $10 \mathrm{~kg} / \mathrm{ha}$ ). On four dates (1 December, $11 \mathrm{Jan}$ uary, 12 March, and 25 April) soil columns were divided into layers. The concentration $\left(c^{*}\right)$ in all layers was measured by extracting the soil with ethyl acetate and by analysing the ethyl acetate layer with gas chromatography and a flame photometric detector. The effluent of the soil columns was collected and analysed for ethoprophos: in none of the samples of effluent could ethoprophos be detected (limit of detection: $3 \mathrm{mg} \mathrm{m}^{-3}$ ). Details of experimental procedures have been reported in Smelt et al. (1981).

\section{Description of weather conditions and water flow}

In the model, soil temperature was introduced as a function of time as described by Leistra \& Smelt (1981). This function was based on daily averages of soil temperature as measured at depths of 10 and $20 \mathrm{~cm}$ (see Smelt et al., 1981).

The daily averages of rates of rainfall and evaporation used in the model were those estimated by Leistra \& Smelt (1981). The volume fraction of water at field capacity was derived from the relations between matric pressure and volume fraction of water as used by Leistra \& Smelt (1981). The withdrawal function (withdrawal as a result of evaporation) given by Boesten \& Stroosnijder (1986) was used. 
Estimation of values of parameters in the pesticide model

In the model, the volumic mass of dry soil, $\varrho$, varied with depth, as derived from the measurements of Smelt et al. (1981) for the three soil types (from Wierum, Middenmeer and Rolde). The value of $L_{\text {dis }}$ was for all soil types set at $10 \mathrm{~mm}$, which is an intermediate value in the range of values $(2-30 \mathrm{~mm})$ reported in the literature for columns of undisturbed soil (see review by Boesten, 1986, p. 83). The relationship between the tortuosity factor for diffusion, $\lambda$, and the volume fraction of water, $\theta$, was assumed to be equal for the three soil types and was taken from a compilation of literature data (Leistra, 1978). The coefficient for diffusion of ethoprophos in water, $D_{0}$, was estimated to be $35 \mathrm{~mm}^{2} \mathrm{~d}^{-1}$, using the method of Othmer \& Thakar (Reid \& Sherwood, 1966, p. 550).

The value of the Freundlich exponent, $1 / n$, was set at 1.0 (assuming, as a first approximation, linear sorption isotherms). The same operational definition as before (Boesten, 1986) was used for the distinction between sorption at class- 1 and class-2 sites and sorption at class- 3 sites: sorption at class- 1 plus class- 2 sites is assumed to be at equilibrium at the end of an adsorption experiment in which a suspension of soil is shaken for about $1 \mathrm{~d}$, and sorption at class- 3 sites is assumed to be still negligible at the end of such an experiment. So the sum of $K_{1}$ and $K_{2}$ was set equal to the values of the adsorption coefficients, $K_{\mathrm{s} / 1}$ as estimated by Leistra \& Smelt (1981) for the three soil types. They derived $K_{\mathrm{s} / 1}$ values for the top layer from adsorption experiments done on a suspension of soil and found values of $0.68,0.77$ and $3.4 \mathrm{dm}^{3}$ $\mathrm{kg}^{-1}$ for the soils from Wierum, Middenmeer and Rolde, respectively. For the deeper layers they assumed $K_{\mathrm{s} / 1}$ to decrease with depth in proportion to the decrease of organic matter content with depth. It was assumed that $K_{1}$ was equal to $0.7 K_{\mathrm{s} / \mathrm{l}}$ and that $K_{2}$ was equal to $0.3 K_{\mathrm{s} / 1}$. This subdivision was based on the results of my experiments on short-term sorption kinetics with the herbicide cyanazine in a loamy sand soil (Boesten, 1986, p. 127). The value of $K_{3}$ was assumed to be equal to $0.3 K_{\mathrm{s} / \mathrm{l}}$ (based on $K_{3}$ values found for cyanazine: Boesten, 1986, p. 188). The values for the desorption rate constants $k_{2}$ and $k_{3}$ were assumed to be equal to those found earlier (Boesten, 1986, p. 131 and p. 177) for cyanazine, i.e. $k_{2}=0.5 \mathrm{~d}^{-1}$ and $k_{3}=$ $0.02 \mathrm{~d}^{-1}$.

The transformation rate coefficient, $k_{\mathrm{t}}^{*}$, was assumed to vary with soil temperature, as described by Leistra \& Smelt (1981). For the soil from Rolde, the $k_{\mathrm{t}}^{*}$ values were equal to those used by Leistra \& Smelt. For the soils from Wierum and Middenmeer, Leistra \& Smelt found that their calculations (which were based on $k_{\mathrm{t}}^{*}$ values measured in the laboratory) overestimated the fractions of the dose still present in the soil columns in the second half of the experimental period. Because volatilization of ethoprophos from the soil surface can be ignored (Leistra, 1979), the faster decline measured in the field is probably the result of the transformation rates being higher in the field than expected from the laboratory experiments. The $k_{\mathrm{t}}^{*}$ values used by Leistra \& Smelt had to be multiplied by 1.3-1.4 to obtain a good description of the field-measured decline of the total mass of pesticide in the soil.

\section{Numerical solution}

The system of Eq. 1 to Eq. 7 was solved numerically with an explicit finite-differ- 
ence method. The soil system was divided into compartments of thicknesses between 20 and $90 \mathrm{~mm}$ (see Leistra \& Smelt, 1981). Euler's method was used to integrate with respect to time; the time step was $0.2 \mathrm{~d}$. A copy of the computer program (written in the simulation language CSMP III; IBM, 1975) is available upon request.

\section{Results and discussion}

Fig. 1 shows that the field-measured decline in the three soil types was described reasonably well. The comparison between measured and calculated concentration profiles after 139 and $182 \mathrm{~d}$ (Fig. 2) shows that the model slightly overestimated the transport as measured in the soil columns. These discrepancies between calculated and measured concentration profiles are similar to those found by Leistra \& Smelt (1981) with a transport model in which sorption equilibrium was assumed and in which the long-term sorption process (i.e. sorption at class-3 sites) was ignored. Such small discrepancies may be the result of, for instance, ignoring the effect of temperature on the values of the Freundlich coefficients or of overestimating the value of the dispersion length, $L_{\mathrm{dis}}$. This is illustrated by Fig. 3: the simulated profile (for Middenmeer soil after 139 d) in this figure was calculated with the lower limit of $L_{\text {dis }}$ values reported in the literature (i.e. $L_{\text {dis }}=2 \mathrm{~mm}$; see Boesten, 1986, p. 83) and with temperature-dependent Freundlich coefficients according to the equation

$$
K_{i}=K_{i, \mathrm{r}}\left\{1+\alpha\left(T-T_{\mathrm{r}}\right)\right\}
$$

in which $K_{i}$ is the Freundlich coefficient $\left(\mathrm{m}^{3 / n} \mathrm{~kg}^{-1 / n}\right)$ of class- $i$ sites $(i=1,2$ or 3$), \mathrm{K}_{i, \mathrm{I}}$ is the $\mathrm{K}_{i}$ at reference temperature $\left(19^{\circ} \mathrm{C}\right), \alpha$ is the temperature coefficient $\left(\mathrm{K}^{-1}\right), \stackrel{T}{T}$ is soil temperature $\left({ }^{\circ} \mathrm{C}\right)$ and $T_{\mathrm{r}}$ is the reference temprature $\left({ }^{\circ} \mathrm{C}\right)$. The reference temperature was set at $19^{\circ} \mathrm{C}$ (an estimate of the temperature at which the sorption ex-

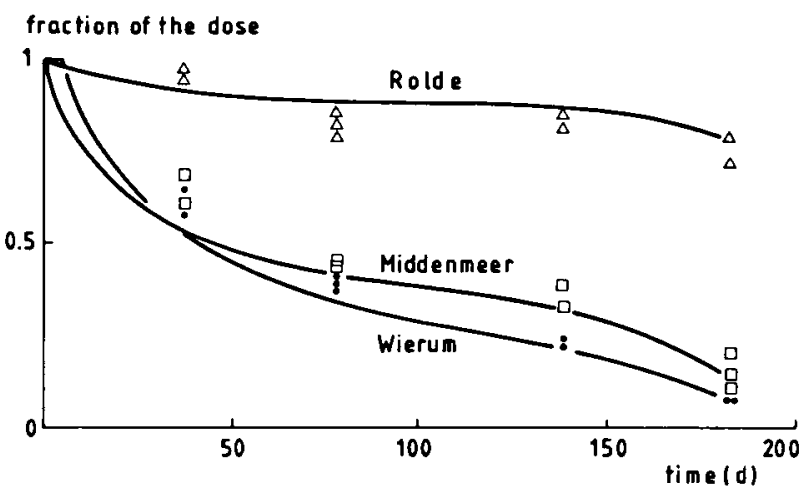

Fig. 1. Calculated and measured decline of ethoprophos in the three soils in the winter half-year. $\triangle, \square$, : measured amounts for the Rolde, Middenmeer and Wierum soils, respectively; lines: simulated with the model. 


\section{J. J. T. I. BOESTEN}

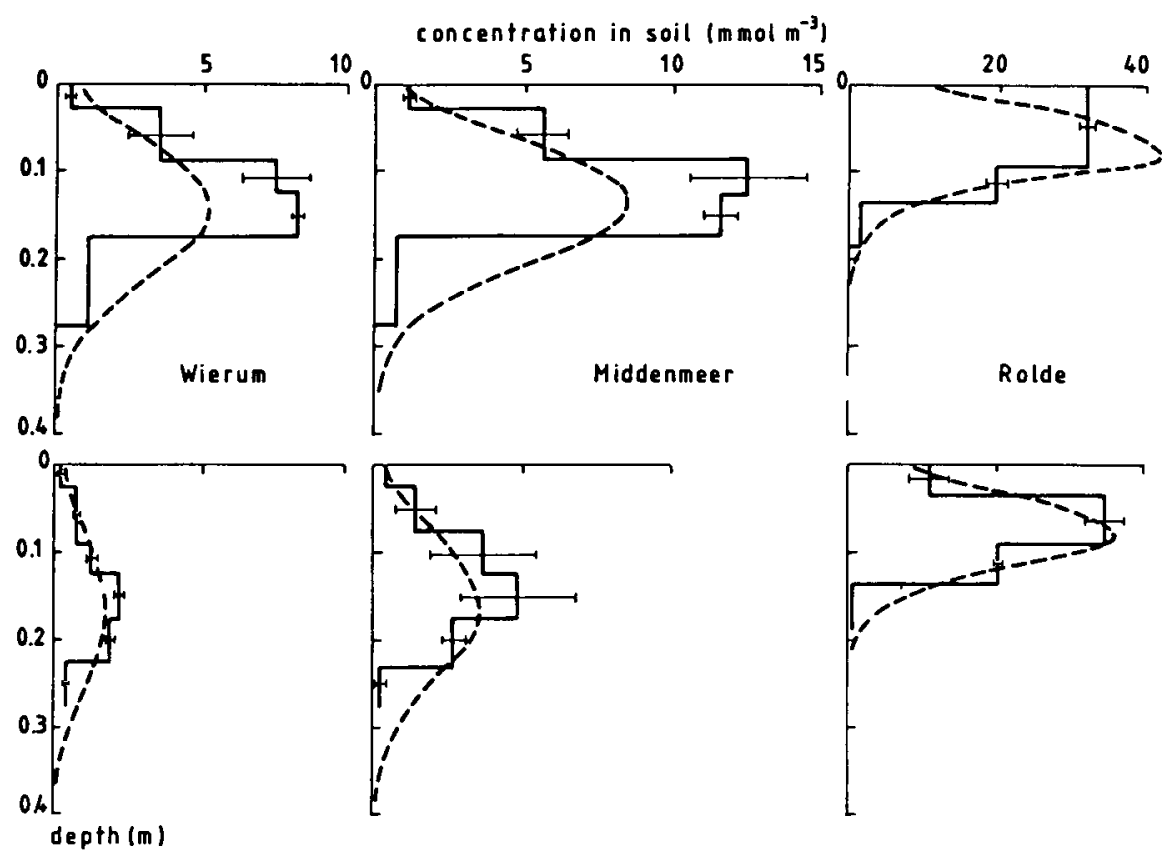

Fig. 2. Comparison of calculated and measured concentration profiles of ethoprophos in the three soil types after $139 \mathrm{~d}$ (upper graphs) and $182 \mathrm{~d}$ (lower graphs). Vertical solid line segments indicate averages of measured concentrations, horizontal bars standard deviations; - - -, calculated.

periments were done). A value of $-0.02 \mathrm{~K}^{-1}$ was used for $\alpha$ (intermediate between the $\alpha$ values found before (Boesten, 1986, p. 146) for cyanazine $\left(\alpha=-0.03 \mathrm{~K}^{-1}\right)$ and for metribuzin $\left(\alpha=-0.01 \mathrm{~K}^{-1}\right)$ in a loamy sand soil). Fig. 3 shows that the concentration profile calculated for Middenmeer soil with Eq. 8 and $L_{\text {dis }}=2 \mathrm{~mm}$ corresponds very well with the average of the measured profiles. This shows that the small discrepancies found in Fig. 2 may be the result of incorrect estimation of parameter values and thus do not refute the transport model.

In the study reported previously (Boesten, 1986), ignoring sorption at class-3

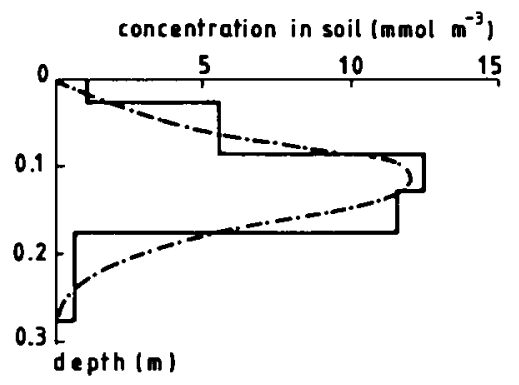

320
Fig. 3. Comparison of the average measured concentration profile $(-)$ of ethoprophos in Middenmeer soil after $139 \mathrm{~d}$ and that calculated (-.-.-) with $L_{\mathrm{dis}}=2 \mathrm{~mm}$ and Eq. 8 (using an $\alpha$ value of $-0.02 \mathrm{~K}^{-1}$ ).

Netherlands Journal of Agricultural Science 35 (1987) 


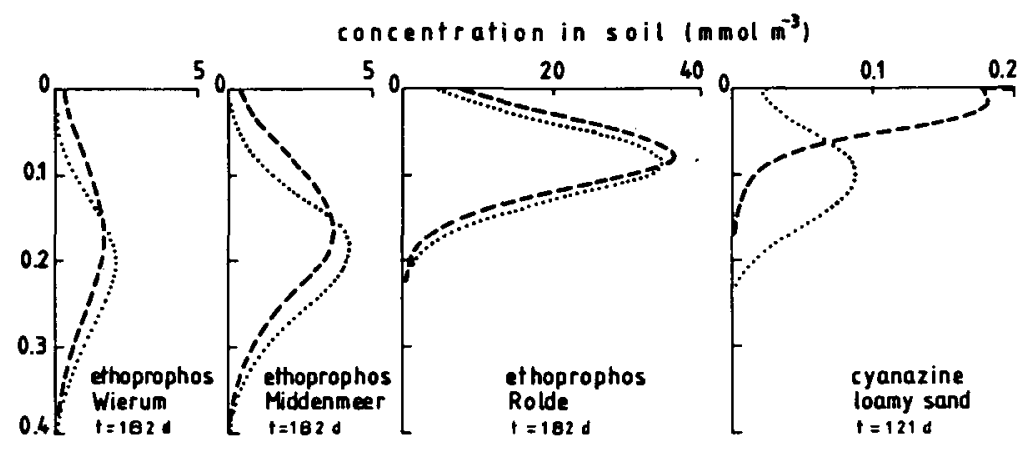

depth $(n)$

Fig. 4. Effect of ignoring sorption at class-3 sites on calculated concentration profiles of ethoprophos at $182 \mathrm{~d}$ after application in the winter half-year and on that of cyanazine at $121 \mathrm{~d}$ after application in the summer half-year; - - , calculated with standard values of $k_{3}$ and $K_{3} ; \ldots$, calculated with $k_{3}=K_{3}=$ 0 .

sites was found to have a large effect on the calculated transport of the herbicide cyanazine $121 \mathrm{~d}$ after application in spring on a loamy sand soil. Fig. 4 shows that ignoring sorption at class- 3 sites had a much smaller effect on the concentration profiles calculated for ethoprophos after $182 \mathrm{~d}$ in the three soil types (after $139 \mathrm{~d}$ the effect was even smaller). The parameters in the sub-model for sorption of ethoprophos by the soils from Wierum and Middenmeer differ only slightly from those for sorption of cyanazine by the loamy sand soil. The difference between cyanazine and ethoprophos with respect to the effect of ignoring sorption at class-3 sites on calculated concentration profiles may be explained by Fig. 5, which shows the course over time of the quotient of $\sigma_{3}$ and $\sigma^{*} ; \sigma_{3}$, the total areic mass of pesticide sorbed onto class- 3 sites $\left(\mathrm{kg} \mathrm{m}^{-2}\right)$, is defined by

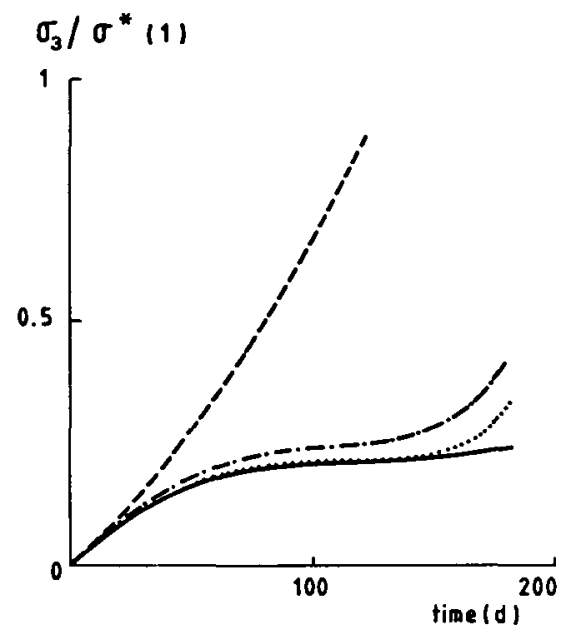

Fig. 5. The course over time of the quotient of $\sigma_{3}$ and $\sigma^{*}$ as calculated for ethoprophos in Rolde (-), Middenmeer $(. . .$.$) and Wierum (-\cdot-\cdot-)$ soils in the winter half-year and for cyanazine $(---)$ in a loamy sand soil in the summer half-year. 


$$
\sigma_{3} \equiv \int_{0}^{Z} \varrho X_{3} \mathrm{~d} z^{\prime}
$$

in which $Z$ is the depth $(\mathrm{m})$ of the soil system considered and in which $z^{\prime}$ is the integration dummy (1) for depth in soil, $z ; \sigma^{*}$, the total areic mass of pesticide in the soil system $\left(\mathrm{kg} \mathrm{m}^{-2}\right)$, is defined by

$$
\sigma^{*} \equiv \int_{0}^{Z} c^{*} \mathrm{~d} z^{\prime}
$$

The $\sigma_{3} / \sigma^{*}$ quotient determines the extent to which sorption at class-3 sites influences the transport in the field: as a result of the slow desorption rate of class -3 sites $\left(k_{3}=0.02 \mathrm{~d}^{-1}\right)$ the pesticide molecules sorbed at class- 3 sites are practically immobile in rainy periods. Fig. 5 shows that for the winter period (the three calculations for ethoprophos) $\sigma_{3} / \sigma^{*}$ increases during the first $50 \mathrm{~d}$ to a value of about 0.2 and remains almost constant thereafter. For the summer period (the calculation for cyanazine), $\sigma_{3} / \sigma^{*}$ increases sharply during the whole simulation period and is near 1.0 after $120 \mathrm{~d}$, indicating that at that moment nearly all the pesticide molecules in the soil system are sorbed at class- 3 sites.

The sharp increase of $\sigma_{3} / \sigma^{*}$ in the summer period is the result of the non-equilibrium aspect of sorption at class -3 sites: if it is assumed that the content sorbed at class3 sites, $X_{3}$, is in equilibrium with the concentration in the liquid phase, $c$, the quotient $\sigma_{3} / \sigma^{*}$ for all pesticide/soil systems considered in Fig. 5 has a value of about 0.2 (estimated with Eq. 4).

Fig. 4 and Fig. 5 show that sorption at class- 3 sites can have a large influence on the calculated concentration profiles only if actual $X_{3}$ values are much higher than $X_{3}$ values at equilibrium conditions. Thus, it is important to assess in which situations $X_{3}$ becomes much higher than its equilibrium value. In a first rough approach, a soil layer was considered in which $c$ is assumed to decrease exponentially with time (as a result, for instance, of leaching or transformation):

$$
c(t)=c(0) \exp \left(-k_{c} t\right)
$$

in which $k_{c}$ is the rate coefficient $\left(\mathrm{d}^{-1}\right)$ for the decline of $c$. If it is assumed that $X_{3}$ is initially zero and that the sorption isotherm for class-3 sites is linear (i.e. $1 / n=1.0$ ), the analytical solution for Eq. 3 may be given by (see van Rootselaar, 1970, p. 131):

$$
X_{3}=\frac{k_{3} K_{3} c(0)}{k_{3}-k_{c}}\left\{\exp \left(-k_{c} t\right)-\exp \left(-k_{3} t\right)\right\}
$$

To describe the deviation of $X_{3}$ from its equilibrium value, the reduced content sorbed at class- 3 sites, $\bar{X}_{3}$, is considered. $\bar{X}_{3}$ is defined as the ratio of the actual value of $X_{3}$ divided by $X_{3, \mathrm{e}}$ i.e. the value of $X_{3}$ that is in equilibrium with the concen- 
tration in liquid phase, $c$. Because $X_{3, \mathrm{e}}$ equals $K_{3} c$, from Eq. 11 and Eq. 12 it may be derived that

$$
\bar{X}_{3}=\frac{k_{3}}{k_{3}-k_{c}}\left[1-\exp \left\{\left(k_{c}-k_{3}\right) t\right\}\right]
$$

Eq. 13 shows that the course over time of $\bar{X}_{3}$ is mainly determined by the difference between $k_{c}$ and $k_{3}$ : if $k_{c}$ is higher than $k_{3}, \bar{X}_{3}$ increases exponentially with time and has no limit. If $k_{c}$ is smaller than $k_{3}, \bar{X}_{3}$ approaches the steady state value of $\left\{k_{3} /\left(k_{3}-k_{c}\right)\right\}$. Fig. 6 shows $\bar{X}_{3}$ as calculated from Eq. 13 for $k_{3}=0.02 \mathrm{~d}^{-1}$ and for a number of $k_{c}: k_{3}$ ratios.

In view of the large effect of the $k_{c}: k_{3}$ ratio in Fig. 6 , the difference between the $\sigma_{3} / \sigma^{*}$ curve for cyanazine and the curves for ethoprophos (shown in Fig. 5) is likely to be the result of differences in transformation rates, the transformation rates in the summer period for cyanazine being higher than those in the winter period for ethoprophos (in all pesticide/soil systems considered almost no leaching occurred below $0.4 \mathrm{~m}$ depth and thus the rate of decline in $c$ is mainly related to the transformation process). The transformation rate of cyanazine could be described with a $k_{t}^{*}$ value of $0.03 \mathrm{~d}^{-1}$ (using Eq. 6) whereas the decline of ethoprophos (shown in Fig. 1) could be described roughly with average $k_{\mathrm{t}}^{*}$ values of $0.002 \mathrm{~d}^{-1}$ for Rolde soil and $0.01 \mathrm{~d}^{-1}$ for both Middenmeer and Wierum soil.

As shown by Fig. 6, the value of $k_{3}$ has to be known accurately if it is in the same order of magnitude as the $k_{c}$ value. Transformation rate coefficients of the majority of the pesticides are in the order of $0.01 \mathrm{~d}^{-1}, \mathrm{i}$.e. in the same order of magnitude as the $k_{3}$ values found before (Boesten, 1986) for two herbicides in a loamy sand soil.

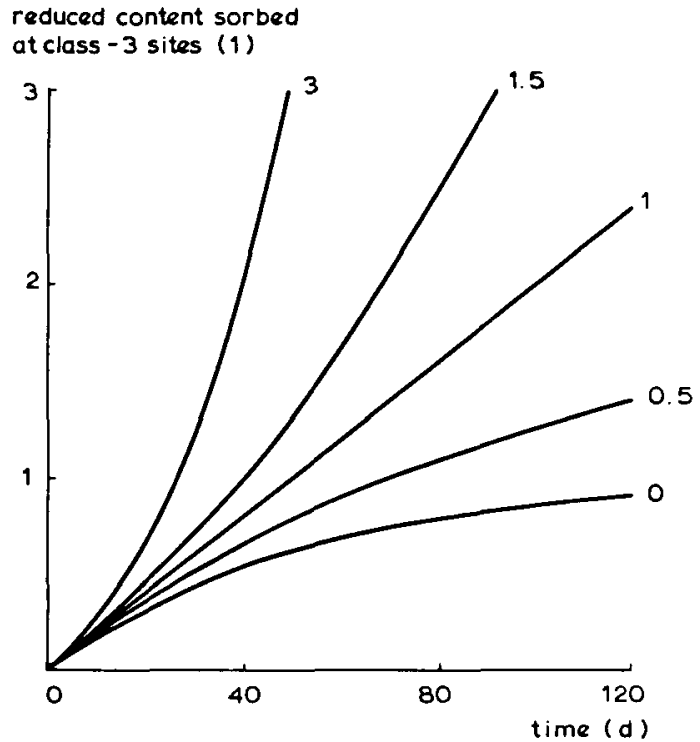

reduced content sorbed
Fig. 6. Reduced content sorbed at class-3 sites, $\bar{X}_{3}$, as a function of time as calculated with Eq. 13 for $k_{3}=0.02 \mathrm{~d}^{-1}$ and for the $k_{c}: k_{3}$ ratios (1) as indicated. 
Thus, it is necessary to measure $k_{3}$ values accurately for the range of pesticide/soil systems in future research, in order to be able to draw general conclusions on the effect of sorption at class-3 sites on the transport of pesticides in the field.

\section{References}

Boesten, J. J. T. I. \& L. Stroosnijder, 1986. Simple model for daily evaporation from fallow tilled soil under spring conditions in a temperate climate. Netherlands Journal of Agricultural Science 34: 75-90.

Boesten, J. J. T. I., 1986. Behaviour of herbicides in soil: simulation and experimental assessment. Doctoral thesis, Wageningen Agricultural University. Institute for Pesticide Research, Wageningen, 263 pp.

Bolt, G. H., 1982. Movement of solutes in soil: Principles of adsorption/exchange chromatography. In: G. H. Bolt (Ed.), Soil chemistry. B. Physico-chemical models, 2nd ed., p. 285-348. Elsevier, Amsterdam.

Hamaker, J. W. \& J. M. Thompson, 1972. Adsorption. In: C. A. I. Goring \& J. W. Hamaker (Eds.), Organic chemicals in the soil environment, p. 49-144. Marcel Dekker, New York.

IBM, 1975. Continuous System Modeling Program III (CSMP III). Program reference manual, Program No 5734-XS9. IBM Data Processing Division, White Plains, NY, USA.

Keulen, H. van, 1975. Simulation of water use and herbage growth in arid regions. Pudoc, Wageningen, $176 \mathrm{pp}$.

Leistra, M., 1978. Computed redistribution of pesticides in the root zone of an arable crop. Plant and Soil 49: 569-580.

Leistra, M., 1979. Computing the movement of ethoprophos in soil after application in spring. Soil Science 128: 303-311.

Leistra, M. \& J. H. Smelt, 1981. Movement and conversion of ethoprophos in soil in winter: 2 . Computer simulation. Soil Science 131: 296-302.

McCall, P. J. \& G. L. Agin, 1985. Desorption kinetics of picloram as affected by residence time in the soil. Environmental Toxicology and Chemistry 4: 37-44.

Reid, R. S. \& T. K. Sherwood, 1966. The properties of gases and liquids. McGraw-Hill, London, 646 pp.

Rootselaar, B. van, 1970. Mathematical analysis. (In Dutch.) Wolters-Noordhoff, Groningen, 266 pp.

Smelt, J. H., M. Leistra, A. Dekker \& C. J. Schut, 1981. Movement and conversion of ethoprophos in soil in winter: 1. Measured concentration patterns and conversion rates. Soil Science 131: 242-248. 